\title{
Prevalence of self-harm among lesbian, gay, bisexual, and transgender adolescents: a comparison of personal and social adversity with a heterosexual sample in Ghana
}

\author{
Emmanuel N.-B. Quarshie ${ }^{1 *} \mathbb{D}$, Mitch G. Waterman² and Allan O. House ${ }^{3}$
}

\begin{abstract}
Objectives: We sought to estimate the prevalence of self-reported self-harm among adolescents identifying as lesbian, gay, bisexual, and transgender (LGBT) in Ghana, and compare self-reported personal and social adversities related to self-harm in this group to those in a random sample of heterosexual adolescents from the same locality.

Results: A total of 444 adolescents aged 13-21 years, comprising 74 LGBT adolescents and 370 heterosexual adolescents, provided data. The lifetime prevalence estimate of self-harm was higher in the LGBT group (47\%) than the heterosexual group (23\%). The LGBT group reported a higher rate of self-harm during the previous 12 months (45\%), compared to the heterosexual group (18\%). LGBT adolescents reported more alcohol and substance use and more personal social adversities, including various forms of victimisation, than heterosexual adolescents. They were no more likely to report difficulty in making and keeping friends or schoolwork problems than were heterosexual adolescents.
\end{abstract}

Keywords: Accra, Adolescents, Ghana, LGBT, Self-harm, Sexual minority, Homosexuality, Street-connected adolescents, Sub-Saharan Africa, Suicide

\section{Introduction}

Across the world, self-harm is the single strongest risk factor for suicide among all age groups $[1,2]$. In subSaharan Africa, suicide remains in the top 12 leading causes of death among young persons aged 10-24 years [3]. Leading researchers and the WHO have reported that young people identifying as in a sexual or gender minority group are at elevated risk of self-harm and eventual suicide compared to heterosexual young people [1, 4-8]. However, neither our own recent systematic literature review [9], nor those of Aggarwal et al. [10], and Lim et al. [11] found studies providing evidence on the

*Correspondence: enquarshie@ug.edu.gh; enquarshie@gmail.com 1 Department of Psychology, University of Ghana, Legon, P.O. Box LG 84, Accra, Ghana

Full list of author information is available at the end of the article prevalence of self-harm in sexual or gender minority young people in countries in sub-Saharan Africa.

Based on previous recommendations [12], we included questions on sexual orientation (lesbian, gay or bisexual) and gender identity (transsexual) in a cross-sectional survey undertaken in the Greater Accra region of Ghana, in 2017; one of our objectives was to estimate the prevalence of self-harm among 2107 adolescents aged 13-21 [13]. Of the 2107 participants, $3.5 \%(n=74)$ self-identified as lesbian, gay, bisexual, and transgender (LGBT). The objective of this research note is to report on the prevalence of self-reported self-harm among those adolescent participants who self-identified as LGBT, and to describe how they compare to a random sample of heterosexual adolescents drawn from the same survey, on personal factors and social adversities related to self-harm. 


\section{Main text Methods}

We have described in detail the participants, sampling and data collection procedures followed in the larger survey [13]. We randomly selected a regionally representative sample of 2107 adolescents: 1723 adolescents across 20 second cycle schools, and 384 street-connected adolescents from four charity facilities and 10 street census enumeration areas within the Greater Accra region of Ghana. The survey used a 4-section questionnaire with 66 items partly developed by the researchers and partly adopted from existing key measures (e.g., the Self-Injurious Thoughts and Behaviors Interview [14], the Suicide Attempt Self-Injury Interview [15], the 2012 WHOGlobal School-based Student Health Survey questionnaire [16]).

We asked a composite question about sexual orientation and gender identity, with response options, "heterosexual", "lesbian", "gay", "bisexual", "transgender". Of the 2107 participants, 2030 self-identified as heterosexual, four indicated that they were lesbian, three identified as gay, 38 as bisexual, and 29 as transgender; three participants did not check any response. We combined all those who replied affirmatively to any of the options into a composite LGBT group $(n=74)$ for the analysis. We used the 'random sample of cases' function in SPSS to draw an analytic comparative random sample of 370 adolescents from the 2030 heterosexual group in a ratio of 5:1, in order to ensure optimal precision of results [17-19].

Lifetime self-harm was assessed with the question, "Have you actually ever intentionally harmed yourself (e.g., cutting, burning, or poisoning yourself, or tried to harm yourself in some other way, for example, hanging, jumping from height etc.)?", while self-harm during the past 12 months was measured with the question, "Did you actually intentionally harm yourself during the past 12 months or 1 year?". The response options for lifetime self-harm and self-harm during the past 12 months were binary: "No" or "Yes". Several questions related to personal factors e.g., sexual orientation worry, alcohol use, and social adversities e.g., conflict with parents, trouble with police, experienced during the previous 12 months, with dichotomous response format ("No" or "Yes") were also included.

We performed descriptive statistical analysis of the data using SPSS (version 26.0 for Windows). We used frequencies and percentages to present the demographic characteristics of the participants and the prevalence estimates of self-harm. We applied $95 \%$ confidence intervals $(\mathrm{CI})$ to assess the uncertainty around the effect estimates of the difference in proportions (DP) between the LGBT and heterosexual groups [20-22].
A preliminary logistic regression analysis showed inflated odds ratios and infinite $95 \%$ confidence intervals due to the small sample size and sparse data. Thus, the present study presents exploratory, descriptive evidence on the prevalence estimates of self-harm among LGBT adolescents in Ghana, and how they compare with heterosexual adolescents on some personal factors and social adversities.

\section{Results}

The mean age of the LGBT sample was 17.1 years $(\mathrm{SD}=1.4$, modal age $=17)$, while the mean age of the heterosexual adolescents was 16.7 years $(\mathrm{SD}=1.4$, modal age $=17$ ). Table 1 presents the demographic characteristics of participants in this study. More females $(n=45$; $60.8 \%)$ identified as LGBT than males $(n=29 ; 39.2 \%)$. Nearly half $(n=36 ; 48.6 \%)$ of the LGBT adolescents reported as coming from families where the father had more than one wife.

\section{Prevalence of self-harm}

As shown in Table 2, the lifetime prevalence of self-harm was higher in the LGBT group (47\%) than the heterosexual group (23\%) [DP 0.24, 95\% CI 0.12-0.36]. Similarly, the LGBT group reported a higher rate of self-harm during the previous 12 months $(44.6 \%)$, compared to the heterosexual group (16.2\%) [DP 0.27, 95\% CI 0.15-0.39].

\section{Personal and social adversity}

The difference in proportions (DP) and associated 95\% CIs (Table 2) show that adolescents identifying as LGBT were more likely than those identifying as heterosexual to report personal level factors such as alcohol use, drug use, and sexual orientation worry during the previous 12 months. Social adversities experienced at higher rates by the LGBT adolescents during the previous 12 months included sexual abuse victimisation, trouble with police, breakup, conflict between parents, and conflict with parents. However, there was no statistically significant difference between the LGBT group and the heterosexual group in terms of having difficulty making or keeping friends, bullying victimisation, schoolwork problems, and attempted suicide in the family.

\section{Discussion}

To the best of our knowledge, this is the first study from Western sub-Saharan Africa providing evidence on the prevalence of self-harm among LGBT adolescents and a comparative group of adolescents identifying as heterosexual. This study has shown that about 4 in 10 adolescents identifying as LGBT, compared to approximately 2 in 10 heterosexual adolescents, report self-harm during the previous 12 months. LGBT adolescents are likely 
Table 1 Demographics of the two study samples

\begin{tabular}{|c|c|c|c|}
\hline \multirow[t]{3}{*}{ Variable } & \multicolumn{2}{|c|}{ Adolescent group } & \multirow{3}{*}{$\begin{array}{l}\text { Difference in proportions } \\
\text { ( } 95 \% \mathrm{Cl} \text { for difference) }\end{array}$} \\
\hline & LGBT $(n=74)$ & Heterosexual $(n=370)$ & \\
\hline & n (\%) & n (\%) & \\
\hline \multicolumn{4}{|l|}{ Adolescent group } \\
\hline In-school & $48(65)$ & $305(82)$ & $-0.17(-0.29,-0.06)$ \\
\hline Street-connected & $26(35)$ & $65(18)$ & $0.17(0.06,0.29)$ \\
\hline \multicolumn{4}{|l|}{ Sex } \\
\hline Male & $29(39)$ & $185(50)$ & $-0.11(-0.23,0.01)$ \\
\hline Female & $45(61)$ & $185(50)$ & $0.11(-0.01,0.23)$ \\
\hline \multicolumn{4}{|l|}{ Age } \\
\hline $13-15$ & $7(9)$ & $69(19)$ & $-0.1(-0.17,-0.01)$ \\
\hline $16-17$ & $36(49)$ & $204(55)$ & $-0.06(-0.19,0.06)$ \\
\hline $18-21$ & $31(42)$ & $97(26)$ & $0.16(0.04,0.28)$ \\
\hline \multicolumn{4}{|l|}{ Family structure } \\
\hline Father has 1 wife & $38(51)$ & $265(72)$ & $-0.21(-0.32,-0.08)$ \\
\hline Father has $>1$ wife & $36(49)$ & $105(28)$ & $0.21(0.08,0.32)$ \\
\hline \multicolumn{4}{|l|}{ Sibling size } \\
\hline$\leq 4$ & $49(66)$ & $252(68)$ & $-0.02(-0.14,0.09)$ \\
\hline$>4$ & $25(34)$ & $118(32)$ & $0.02(-0.09,0.14)$ \\
\hline \multicolumn{4}{|l|}{ Living arrangement } \\
\hline One or both parents & $38(51)$ & $264(71)$ & $-0.2(0.23,0.47)$ \\
\hline Other relation & $14(19)$ & $61(17)$ & $0.02(-0.07,0.12)$ \\
\hline Alone/with another person & $22(30)$ & $45(12)$ & $0.18(0.07,0.28)$ \\
\hline \multicolumn{4}{|l|}{ Religious group } \\
\hline Christian & $57(80)$ & $319(87)$ & $-0.07(-0.19,0.01)$ \\
\hline Muslim & $14(20)$ & $48(13)$ & $0.07(-0.03,0.15)$ \\
\hline \multicolumn{4}{|l|}{ In romantic relationship } \\
\hline No & $30(40)$ & $235(64)$ & $-0.24(-0.35,-0.11)$ \\
\hline Yes & $44(60)$ & $135(36)$ & $0.24(0.11,0.35)$ \\
\hline
\end{tabular}

than heterosexual adolescents to report alcohol and substance use and to be worried about their sexual orientation. LGBT adolescents are likely to report a range of social adversities than heterosexual adolescents. The findings from this study are consistent with what pertains in high-income countries [4-6, 8, 23].

Homosexuality is criminalised in Ghana [24] and culturally tabooed, religiously proscribed, and strongly stigmatised across many countries in Africa [25-27]; about 96\% of Ghanaians oppose homosexuality [26]. Anecdotal reports from Ghana suggest that persons found to be engaged in sexual behaviours considered non-heterosexual have been arrested by the police for prosecution [28, 29], some have been thrown out or disowned by their families [26, 29], while students have been suspended or expelled by school authorities for 'coming out' as nonheterosexual [30,31]. A recent study on vigilantism in Ghana reports that some individuals have been labelled homosexual and assaulted by community members, because those individuals exhibited (sexual) behaviours that were considered stereotypically opposite to their sex [32]. This environment of criminality, social hostility, stigma, tension and strong heteronormativity, as found also in high-income countries [33, 34], gives rise to increased vulnerability of persons identifying as sexual and gender minorities to negative health outcomes and risky health behaviours including alcohol and substance use and abuse, self-harm, and suicide [35-38].

While sexual orientation is widely discussed in the literature as a risk for mental health problems, gender identity is much less so. One reason may be that it is under-recognised as a health issue [39]. However, the World Health Organisation has recognised the need for more focused intervention in this area [1], raising the possibility of more active intervention to improve the health of LGBT young people in sub-Saharan Africa.

While homosexual related legislation does not necessarily lead to reductions in self-harm and suicide in 
Table 2 Difference in proportions between LGBT and heterosexual adolescents across personal factors and social adversities experienced in the previous 12 months

\begin{tabular}{|c|c|c|c|c|}
\hline \multirow[t]{2}{*}{ Variable } & \multicolumn{2}{|c|}{ Adolescent group } & \multirow{2}{*}{\multicolumn{2}{|c|}{$\begin{array}{l}\text { Difference in proportions }(95 \% \mathrm{Cl} \\
\text { for difference) }\end{array}$}} \\
\hline & $\begin{array}{l}\text { LGBT }(n=74) \\
n(\%)\end{array}$ & $\begin{array}{l}\text { Heterosexual }(n=370) \\
n(\%)\end{array}$ & & \\
\hline \multicolumn{5}{|l|}{ Self-reported self-harm } \\
\hline Lifetime self-harm & $35(47)$ & $85(23)$ & 0.24 & $(0.12,0.36)$ \\
\hline Self-harm in the past 12 months & $33(45)$ & $65(18)$ & 0.27 & $(0.15,0.39)$ \\
\hline Suicide in family & $11(15)$ & $10(3)$ & 0.12 & $(0.04,0.20)$ \\
\hline Attempted suicide in family & $14(19)$ & $37(10)$ & 0.09 & $(-0.01,0.18)$ \\
\hline Friend suicide & $12(16)$ & $15(4)$ & 0.12 & $(0.03,0.21)$ \\
\hline Friend attempted suicide & $22(30)$ & $39(11)$ & 0.19 & $(0.08,0.30)$ \\
\hline \multicolumn{5}{|l|}{ Alcohol and substance use } \\
\hline Alcohol use & $35(47)$ & $54(14)$ & 0.33 & $(0.21,0.45)$ \\
\hline Cigarette smoking & $16(21)$ & $5(1)$ & 0.20 & $(0.11,0.29)$ \\
\hline Drug use & $19(25)$ & $14(3)$ & 0.22 & $(0.12,0.32)$ \\
\hline \multicolumn{5}{|l|}{ Family conflict } \\
\hline Conflict between parents & $41(55)$ & $153(41)$ & 0.14 & $(0.02,0.26)$ \\
\hline Conflict with parents & $28(37)$ & $94(25)$ & 0.12 & $(0.01,0.24)$ \\
\hline \multicolumn{5}{|l|}{ Other social problems } \\
\hline Conflict with friends & $47(63)$ & $183(49)$ & 0.14 & $(0.02,0.26)$ \\
\hline Breakup & $28(37)$ & $76(20)$ & 0.17 & $(0.05,0.29)$ \\
\hline Difficulty making/keeping friends & $25(34)$ & $134(36)$ & -0.02 & $(-0.14,0.09)$ \\
\hline Sexual orientation worry & $20(27)$ & $10(3)$ & 0.24 & $(0.14,0.35)$ \\
\hline \multicolumn{5}{|l|}{ Other problems } \\
\hline Schoolwork problems & $24(32)$ & $117(31)$ & 0.1 & $(-0.11,0.12)$ \\
\hline Bullying victimisation & $36(48)$ & $134(36)$ & 0.12 & $(0.00,0.25)$ \\
\hline Sexual abuse victimisation & $38(51)$ & $8(10)$ & 0.41 & $(0.38,0.61)$ \\
\hline Physical abuse victimisation & $44(59)$ & $148(40)$ & 0.19 & $(0.07,0.32)$ \\
\hline Trouble with police & $18(24)$ & $24(6)$ & 0.18 & $(0.08,0.28)$ \\
\hline
\end{tabular}

members of sexual or gender minorities [40], it is now well documented that pro-homosexual legislation, together with acceptances by others, supportive family and public attitudes and secure environment, have the potential of leading to positive health outcomes in persons identifying as sexual or gender minority [36, 41-43].

The evidence of this study underscores the need for families, school staff, social and healthcare professionals to show positive attitudes and be supportive of LGBT adolescents, thereby creating a secure environment to reduce vulnerabilities and risks to self-harm. Similarly, besides developing welcoming attitudes to LGBT young people, leaders of religious institutions (e.g., schools) and organisations (e.g., churches, mosques) could consider collaborating with the mass media to begin public education programmes aimed at changing negative attitudes and working towards removing the predominant sociocultural factors which give rise to hostilities against sexual and gender minorities in Ghana.

\section{Limitations}

The small sample size of adolescents identifying as LGBT in our larger cross-sectional survey sample in the Greater Accra Region made it impossible to use more robust multivariate statistical modelling techniques to stratify the analysis by sexual orientation categories, gender, and whether the young people were in school or street-connected.

Also, all the participants were accessed within the Greater Accra Region of Ghana-which is entirely urbanised. Therefore, our results may not be necessarily generalisable across LGBT adolescents in rural Ghana.

Social desirability bias is possible-some of the adolescents actually identifying as LGBT might have checked the heterosexual orientation response option in the larger study. However, it is notable that 74 adolescents checked one of the LGBT options-a sample size that is high compared to a recent study of suicidal behaviours among college students in Ghana [44]. 
Clearly, more studies on the health and well-being of young people identifying as LGBT are needed from Ghana, and sub-Saharan Africa. Thus far across subSaharan Africa, only one study from South Africa has been published on the personal experiences of attempted suicide by two students who identify as gay [45]. In particular, future qualitive studies on self-harm exploring the first-hand accounts of LGBT young people would be potentially informative in mapping out future studies and informing prevention and intervention strategies.

The general homophobic environment and social hostilities make sexual and gender minorities a hard-toreach population for research in sub-Saharan Africa. Future research could consider the use of online research techniques which increase access to this young population and also ensure anonymity of participants [46]. Potentially, school-based and street-based sexual health education programmes could benefit from evidence of such future studies to help young people who have sexual orientation or gender identity concerns.

\section{Abbreviations \\ Cl: Confidence interval; DP: Difference in proportions; LGBT: Lesbian, gay, bisexual, and transgender; SPSS: Statistical Package for the Social Sciences; WHO: World health Organisation.}

\section{Acknowledgements}

We thank all the key stakeholders who granted permissions for this study: heads of the participating schools, directors and management of the selected charity organisations, the Greater Accra Regional Office of the Ghana Education Service, the Department of Social Welfare headquarters, Accra, and parents/guardians of the underage participants. Also, we thank all the participants who contributed the data about their self-harm for this study.

\section{Authors' contributions}

$E Q, M W$ and $A H$ contributed to the study concept and design; EQ performed statistical analysis of the data and drafted the manuscript, and MW and $\mathrm{AH}$ critiqued the manuscript for important intellectual content. All the authors contributed to the interpretation of results. All authors read and approved the final manuscript.

\section{Funding}

This study was supported by the Leeds International Research Scholarship (LIRS) at the University of Leeds, School of Psychology, in the form of a doctoral scholarship to the first author (EQ) - [Grant No: CFN/sy/200631403]. The funder of the study had no role in study design, data collection, data analysis, data interpretation, or writing of the report. The views expressed in this paper are those of the authors and not necessarily those of the LIRS.

\section{Availability of data and materials}

The datasets used and/or analysed during the current study are available from the corresponding author on reasonable request.

\section{Ethics approval and consent to participate}

This study received ethical approval from two Institutional Review Boards (the School of Psychology Ethics Committee, University of Leeds, UK, [Ref. №. 16-0373] and the Ethics Committee for the Humanities, University of Ghana, Accra, Ghana [Ref. №: ECH078/16-17]) and institutional permissions were also obtained to conduct this study. The participants signed a consent form prior to taking part in the interview. The consent of the parents/guardians of in-school adolescents aged 13-17 years was sought, while the underage adolescents assented to participate. Consent to participate in the study was sought from the management of charity facilities and street social workers on behalf of street-connected adolescents aged 13-17 years. We have pseudoanonymised or completely anonymised all potentially identifying information including specific names of schools and charity facilities where participants were approached.

\section{Consent for publication}

Not applicable.

\section{Competing interests}

The authors declare that they have no competing interests.

\section{Author details}

${ }^{1}$ Department of Psychology, University of Ghana, Legon, P.O. Box LG 84, Accra, Ghana. ${ }^{2}$ School of Psychology, University of Leeds, Leeds, UK. ${ }^{3}$ Leeds Institute of Health Sciences, University of Leeds, Leeds, UK.

Received: 3 March 2020 Accepted: 25 May 2020

Published online: 03 June 2020

\section{References}

1. World Health Organization. Preventing suicide, a global imperative. Geneva: WHO; 2014.

2. World Health Organization. Practice manual for establishing and maintaining surveillance systems for suicide attempts and self-harm. Geneva: WHO; 2016.

3. Naghavi M. Global burden of disease self-harm collaborators: global, regional, and national burden of suicide mortality 1990 to 2016: Systematic analysis for the Global Burden of Disease Study 2016. BMJ. 2019;364:194. https://doi.org/10.1136/bmj.194.

4. King M, Semlyen J, Tai SS, Killaspy H, Osborn D, Popelyuk D, Nazareth I. A systematic review of mental disorder, suicide, and deliberate self harm in lesbian, gay and bisexual people. BMC Psychiatry. 2008;8(1):70. https:// doi.org/10.1186/1471-244X-8-70.

5. Marshal MP, Dietz LJ, Friedman MS, Stall R, Smith HA, McGinley J, Thoma BC, Murray PJ, D’Augelli AR, Brent DA. Suicidality and depression disparities between sexual minority and heterosexual youth: a meta-analytic review. J Adolesc Health. 2011;49(2):115-23. https://doi.org/10.1016/j. jadohealth.2011.02.005.

6. Plöderl M, Tremblay P. Mental health of sexual minorities. A systematic review. Int Rev Psychiatry. 2015;27(5):367-85. https://doi. org/10.3109/09540261.2015.1083949.

7. Liu RT, Sheehan AE, Walsh RF, Sanzari CM, Cheek SM, Hernandez EM. Prevalence and correlates of non-suicidal self-injury among lesbian, gay, bisexual, and transgender individuals: a systematic review and metaanalysis. Clin Psychol Rev. 2019;74:101783. https://doi.org/10.1016/j. cpr.2019.101783.

8. Miranda-Mendizábal A, Castellví P, Parés-Badell O, Almenara J, Alonso I, Blasco M, Cebrià A, Gabilondo A, Gili M, Lagares C. Sexual orientation and suicidal behaviour in adolescents and young adults: systematic review and meta-analysis. Br J Psychiatry. 2017;211(2):77-87. https://doi. org/10.1192/bjp.bp.116.196345.

9. Quarshie ENB, Waterman MG, House AO. Self-harm with suicidal and non-suicidal intent in young people in sub-Saharan Africa: a systematic review. BMC Psychiatry. 2020;20(234):1-26. https://doi.org/10.1186/s1288 8-020-02587-z.

10. Aggarwal S, Patton G, Reavley N, Sreenivasan SA, Berk M. Youth self-harm in low-and middle-income countries: systematic review of the risk and protective factors. Int J Soc Psychiatry. 2017;63(4):359-75. https://doi. org/10.1177/0020764017700175.

11. Lim K-S, Wong CH, Mclntyre RS, Wang J, Zhang Z, Tran BX, Tan W, Ho CS, Ho RC. Global lifetime and 12-month prevalence of suicidal behavior, deliberate self-harm and non-suicidal self-injury in children and adolescents between 1989 and 2018: a meta-analysis. Int J Environ Res Public Health. 2019;16(22):4581. https://doi.org/10.3390/ijerph16224581.

12. Dilley JA, Simmons KW, Boysun MJ, Pizacani BA, Stark MJ. Demonstrating the importance and feasibility of including sexual orientation in public health surveys: health disparities in the Pacific Northwest. Am J Public Health. 2010;100(3):460-7. https://doi.org/10.2105/AJPH.2007.130336. 
13. Quarshie ENB, Shuweihdi F, Waterman MG, House AO. Self-harm among in-school and street-connected adolescents in Ghana: A cross-sectional survey in the Greater Accra Region. 2020. Manuscript submitted for publication.

14. Nock MK, Holmberg EB, Photos VI, Michel BD. Self-Injurious Thoughts and Behaviors Interview: development, reliability, and validity in an adolescent sample. Psychol Assess. 2007;19(3):309-17. https://doi. org/10.1037/1040-3590.19.3.309.

15. Linehan MM, Comtois KA, Brown MZ, Heard HL, Wagner A. suicide attempt self-injury interview (SASII): development, reliability, and validity of a scale to assess suicide attempts and intentional self-injury. Psychol Assess. 2006;18(3):303-12. https://doi.org/10.1037/1040-3590.18.3.303.

16. Owusu A. Global school-based student health survey (GSHS): Ghana report. Murfreesboro: Middle Tennessee State University, Ghana Education Service, \& WHO; 2012

17. Ury HK. Efficiency of case-control studies with multiple controls per case: continuous or dichotomous data. Biometrics. 1975;31(3):643-9. https:// doi.org/10.2307/2529548.

18. Austin PC. Statistical criteria for selecting the optimal number of untreated subjects matched to each treated subject when using many-to-one matching on the propensity score. Am J Epidemiol. 2010;172(9):1092-7. https://doi.org/10.1093/aje/kwq224.

19. Rassen JA, Shelat AA, Myers J, Glynn RJ, Rothman KJ, Schneeweiss S. One-to-many propensity score matching in cohort studies. Pharmacoepidemiol Drug Saf. 2012;21:69-80. https://doi.org/10.1002/pds.3263.

20. Sullivan GM, Feinn R. Using effect size - or why the $p$ value is not enough. J Grad Med Educ. 2012;4(3):279-82. https://doi.org/10.4300/jgmed-12-00156.1.

21. Greenland S, Senn SJ, Rothman KJ, Carlin JB, Poole C, Goodman SN, Altman DG. Statistical tests, P values, confidence intervals, and power: a guide to misinterpretations. Eur J Epidemiol. 2016;31(4):337-50. https:// doi.org/10.1007/s10654-016-0149-3.

22. Hespanhol L, Vallio CS, Costa LM, Saragiotto BT. Understanding and interpreting confidence and credible intervals around effect estimates. Braz J Phys Ther. 2019;23(4):290-301. https://doi.org/10.1016/j.bjpt.2018.12.006.

23. Plöderl M, Wagenmakers E-J, Tremblay P, Ramsay R, Kralovec K, Fartacek C, Fartacek R. Suicide risk and sexual orientation: a critical review. Arch Sex Behav. 2013;42(5):715-27. https://doi.org/10.1007/s10508-012-0056-y.

24. Act 29 of Ghana. The criminal offences act, 1960. Accra, Ghana: Assembly Press; 1960

25. Gyekye K. African cultural values. An introduction. Accra, Ghana: Sankofa publishing company; 2003.

26. Kaoma K. Christianity, globalization, and protective homophobia. Cham: Springer; 2018

27. Thoreson R, Cook S, editors. Nowhere to turn: blackmail and extortion of LGBT people in Sub-Saharan Africa. Brooklyn: International Gay and Lesbian Human Rights Commission; 2011.

28. Police arrests two girls over lesbianism in Kumasi. https://www.newsg hana.com.gh/police-arrests-two-girls-over-lesbianism-in-kumasi/.

29. Human Rights Watch. "No Choice but to Deny Who I Am". Violence and Discrimination against LGBT People in Ghana. New York: Human Rights Watch; 2018.

30. Pope John suspends two "gay" students. https://www.graphic.com.gh/ news/general-news/pope-john-suspends-two-gay-students.html.

31. Two Ghana schools expel 53 students for being gay. https://www.gayst arnews.com/article/two-ghana-schools-expel-53-students-being-gay19 0413/.
32. Adzimah-Alade M, Akotia CS, Annor F, Quarshie ENB. Vigilantism in Ghana: Trends, victim characteristics, and reported reasons. Howard J Crime Just. 2020;1:1. https://doi.org/10.1111/hojo.12364.

33. Taliaferro LA, McMorris BJ, Rider GN, Eisenberg ME. Risk and protective factors for self-harm in a population-based sample of transgender youth. Arch Suicide Res. 2019;23(2):203-21. https://doi.org/10.1080/13811 118.2018 .1430639$.

34. Taylor PJ, Dhingra K, Dickson JM, McDermott E. Psychological correlates of self-harm within gay, lesbian and bisexual UK university students. Archiv Suicide Res. 2018. https://doi.org/10.1080/13811118.2018.1430639.

35. McDermott E, Roen K. Queer youth, suicide and self-Harm. Troubled subject, troubling norms. London: Palgrave Macmillan; 2016.

36. Rimes KA, Shivakumar S, Ussher G, Baker D, Rahman Q, West E. Psychosocial factors associated with suicide attempts, ideation, and future risk in lesbian, gay, and bisexual youth: the Youth Chances study. Crisis. 2019:40(2):83-92. https://doi.org/10.1027/0227-5910/a000527.

37. Oginni OA, Mapayi BM, Afolabi OT, Ebuenyi ID, Akinsulore A, Mosaku KS. Association between risky sexual behavior and a psychosocial syndemic among Nigerian men who have sex with men. J Gay Lesbian Mental Health. 2019;23(2):168-85. https://doi.org/10.1080/19359705.2018.15526 40

38. Oginni OA, Mapayi BM, Afolabi OT, Obiajunwa C, Oloniniyi IO. Internalized Homophobia, Coping, and Quality of Life Among Nigerian Gay and Bisexual Men. J Homosex. 2019. https://doi.org/10.1080/00918369.2019.16008 99.

39. Jobson GA, Theron LB, Kaggwa JK, Kim H-J. Transgender in Africa: invisible, inaccessible, or ignored? Sahara J. 2012;9(3):160-3. https://doi. org/10.1080/17290376.2012.743829

40. Mathy RM. Homosexual related legislation does not reduce suicidal intent in sexual minority groups. BMJ. 2002;325(7373):1176. https://doi. org/10.1136/bmj.325.7373.1176.

41. Poštuvan V, Podlogar T, Šedivy NZ, De Leo D. Suicidal behaviour among sexual-minority youth: a review of the role of acceptance and support. Lancet Child Adoles Health. 2019;3(3):190-8. https://doi.org/10.1016/ S2352-4642(18)30400-0.

42. McDermott E, Gabb J, Eastham R, Hanbury A. Family trouble: heteronormativity, emotion work and queer youth mental health. Health. 2019. https://doi.org/10.1177/1363459319860572.

43. Bagley C, D'Augelli AR. Suicidal behaviour in gay, lesbian, and bisexual youth: it's an international problem that is associated with homophobic legislation. BMJ. 2000;320:1617-8. https://doi.org/10.2307/25224814.

44. Quarshie ENB, Cheataa-Plange HV, Annor F, Asare-Doku W, Lartey JKS. Prevalence of suicidal behaviour among nursing and midwifery college students in Ghana. Nurs Open. 2019;6(3):897-906. https://doi. org/10.1002/nop2.271.

45. Meissner BL, Bantjes J. Disconnection, reconnection and autonomy: four young South African men's experience of attempting suicide. J Youth Stud. 2017;20(7):781-97. https://doi.org/10.1080/13676261.2016.12735 12.

46. McDermott E, Roen K, Piela A. Hard-to-reach youth online: methodological advances in self-harm research. Sex Res Social Policy. 2013;10(2):12534. https://doi.org/10.1007/s13178-012-0108-z.

\section{Publisher's Note}

Springer Nature remains neutral with regard to jurisdictional claims in published maps and institutional affiliations. 